\title{
A produção de telejornais e telenovelas em tempos de crise do capital
}

\section{Antonio Cícero Cassiano Sousa}

Doutor em História e professor e pesquisador no CEPPES (Centro de Educação Popular e Pesquisas Econômicas e Sociais), no ISERJ (Instituto Superior de Educação) e ETAB (Escola Técnica Estadual Adolpho Bloch), Rio de Janeiro, Brasil.

\section{Resumo}

O artigo tem como hipótese central que as transformações recentes no modo de produção capitalista subvertem o papel tradicional do telejornalismo, tornando-o menos propenso reivindicar neutralidade e reafirma o papel de mobilização emocional da teledramaturgia.

Palavras-chave: televisão, telejornalismo, teledramaturgia, revolução científico-técnica, telerrealidade.

\section{Abstract}

The central hypothesis is that the recent transformations in capitalist way of production overthrow the traditional paper of the telejournalism and reaffirm the emotional mobilization paper of the teledramaturgy.

Key words: television, telejournalism, teledramaturgy, scientific-technician revolution, telerreality.

\section{Resumen}

El artículo tiene como hipótesis central que las transformaciones actuales en el modo de producción capitalista subvierten el papel tradicional del teleperiodismo, haciendo que sean menos capaces de reivindicar neutralidad e asegurar el papel de movilización emocional de la teledramaturgia.

Palabras llaves: televisión, teleperiodismo, teledramaturgia, revolución científico-técnica, telerealidad.

\section{Introdução}

O objetivo deste artigo é levantar hipóteses a partir de estudos recentes sobre telenovela e telejornalismo para observar como a linguagem televisiva se estruturou a luz das modificações trazidas pela revolução científico-técnica e pelo retorno das crises cíclicas do capitalismo.

A bibliografia consultada divide-se em dois blocos: aquele que se volta para a formação do modo de produção capitalista e seu desenvolvimento, especialmente as obras que abordam a chamada revolução científico-técnica e o caráter da crise capi- 
talista atual; da mesma forma merece atenção a bibliografia que trata dos aspectos específicos do meio técnico televisão e da produção de telenovelas e telejornalismo.

Podemos afirmar que a revolução científico-técnica é uma revolução nas comunicações, pois o que está em jogo é o mecanismo de transmissão de informações da máquina, antecedido pela máquina-ferramenta e pela máquina-motriz. A consequência mais visível é a quantidade de informações que circulam no mundo a partir do advento da era informacional.

Sabe-se que a produção de bens culturais é especialmente atingida pelas condições econômicas, que determinam a produção propriamente dita do bem cultural, mas também produzem o gosto à medida que a produção também determina o consumo: "A produção não produz, pois unicamente o objeto do consumo, mas também o modo de consumo, ou seja, não objetiva, como subjetivamente. Logo, a produção cria o consumidor" (MARX, 1978, p. 110). No caso dos bens culturais, o gosto adquire certa autonomia que justifica, por exemplo, o papel da crítica cultural. A abrangência da crise atual poderia estar afetando de forma mais intensa a produção de produtos televisivos, assim como atinge a ciência e a educação:

"A crise do capital atual, como relação e processo generalizado por todo o sistema do capital mundializado (desde o final do século XIX), é uma crise geral que afirma a passagem do desenvolvimento do capital ao estágio de negação de sua própria lógica de reprodução, como relação e processo social dominantes da sociedade humana em geral e historicamente determinada em particular, segundo sua singularidade essencial. É uma crise que traduz a essência contraditória da organicidade da produção que se autorreproduz negando o produto ao seu produtor e o valor essencial que contém o mesmo: a reprodução humana, a vida" (BEVILAQUA, 2011, p. 256).

Os próximos passos dessa pesquisa visam responder de que forma a crise estaria incidindo na produção de telejornais, tornando suas mensagens mais ideologizadas; por outro lado, aparentemente estaria desideologizando a produção de entretenimento, no caso da teledramaturgia.

A televisão tem uma linguagem específica, embora reproduza elementos fundamentais de outras mídias como rádio e cinema.

O primeiro aspecto específico da linguagem televisiva era o formato curvo da tela, que "arredondava" a imagem, estabelecendo uma tridimensionalidade diferente da imagem cinematográfica. Essa característica vem se diluindo com os novos tipos de monitores de telas planas e a introdução do padrão digital.

O segundo aspecto é a predominância da edição acelerada. Velocidade e excesso de imagens estão mais presentes na televisão do que em qualquer outra mídia audiovisual. Para isso, se faz necessário a adoção de planos e sequências breves, construindo o ritmo rápido da linguagem. Velocidade no corte, mas pouco movimento de câmera, que devem ser mínimos. $\mathrm{Na}$ análise que fez das novelas Fogo sobre terra e $A$ corrida do ouro, Van Tilburg localizou uma proporção bastante pequena de travellings ou panorâmicas ${ }^{1}$ : do total de tomadas analisadas somente em $29,7 \%$ a câmera estava em movimento (TILBURG, 1990, p. 78). Comparando o tempo de duração das tomadas das novelas da Globo com outras emissoras, verificou que as tomadas destas tinham

1 Travelling é o movimento da câmera em direção ao objeto, com possibilidades de alterações de grande amplitude no enquadramento, panorâmica é o movimento da câmera em torno do próprio eixo, sendo assim mais descritivo e uniforme. 
o dobro daquela, da mesma forma observou um percentual maior de tomadas com 1 ou 2 personagens nas novelas da Globo (TILBURG, 1990, pp. 79-90).

No plano da construção dramática, Marcos Rey localizou um aumento acentuado da quantidade de cenas por capítulos em telenovelas: de uma média de 10 cenas nas primeiras telenovelas, passou-se para cerca de 40 nas atuais (REY, 2003, p. 49).

No lugar dos movimentos de câmera, adota-se com frequência o recurso do campo e contracampo (enquadramentos alternados feitos por duas câmeras em diagonal). Trata-se de planos muito usados nas telenovelas por se prestarem bem às cenas de diálogo. Tilburg associa essa codificação da imagem à adequação ao esforço físico do telespectador médio: depois de uma jornada exaustiva de trabalho, ele não deve ser sobrecarregado com mais esforço no acompanhamento da mensagem televisiva daí a economia de movimentos de câmera e presença de poucos personagens em cena, da mesma forma, evita-se os planos longos, que lhe exigiriam maior dispêndio de concentração.

O terceiro aspecto é a justaposição de informação, particularmente presente na programação jornalística. O porquê, o para quê e o como desaparecem, impedindo que o telespectador estabeleça relações mais substantivas e complexas sobre o fato (FISHER, 2003, 104).

Podemos falar também da função fática ${ }^{2}$, como quarto aspecto da linguagem televisiva. A mensagem na TV chega ao receptor com grande naturalidade; a programação vai até ele, ao contrário de outras modalidades de espetáculo. Cabe a ela, por excelência, a função fática na medida em que estabelece essa familiaridade com o espectador (CAMPDELLI, 1985, pp. 16-17).

Marcos Rey, ao distinguir escrever para TV e escrever para cinema, afirma que na telenovela a atenção total do telespectador não é exigida, ele pode fazer coisas como fumar, tomar café, ir ao banheiro: "Em suma, quando se escreve para o cinema pensa-se no público, quando se escrever para a televisão pensa-se no espectador. $\mathrm{O}$ diálogo no cinema tem que servir para todos. Na televisão é só para a pessoa que se sentou diante do aparelho" (REY, 2003, p. 129). Assistir televisão supõe tal grau de dispersão que se impõe segmentos e intervalos, mesmo que não haja comerciais que os justifiquem. Note-se que nas TVs públicas também há intervalos. Para quê? Como o ambiente doméstico tem uma infinidade de outros estímulos, a TV pode ser apenas um entre muitos.

No primeiro capítulo examinaremos a relação da televisão com a publicidade, destacando sua relação com o modo de produção e da criação de hábitos de consumo e subjetividade. No capítulo seguinte veremos a TV como meio de programação social dos comportamentos. Nos dois capítulos sobre telejornalismo e teledramaturgia apresentaremos como esses dois gêneros se constituem na formação da chamada telerrealidade e na mobilização emocional, respectivamente. Examinemos agora o objeto e sua relação com a publicidade e com a programação social do comportamento.

\section{Televisão e publicidade}

O capitalismo da segunda metade do século XX está marcado por sua relação com as novas formas de transmissão de informação, particularmente a televisão. Analisando

2 Função fática é a linguagem que consiste na verificação do funcionamento do canal de comunicação, através de expressões como "alô", "oi”, "tudo bem?". 


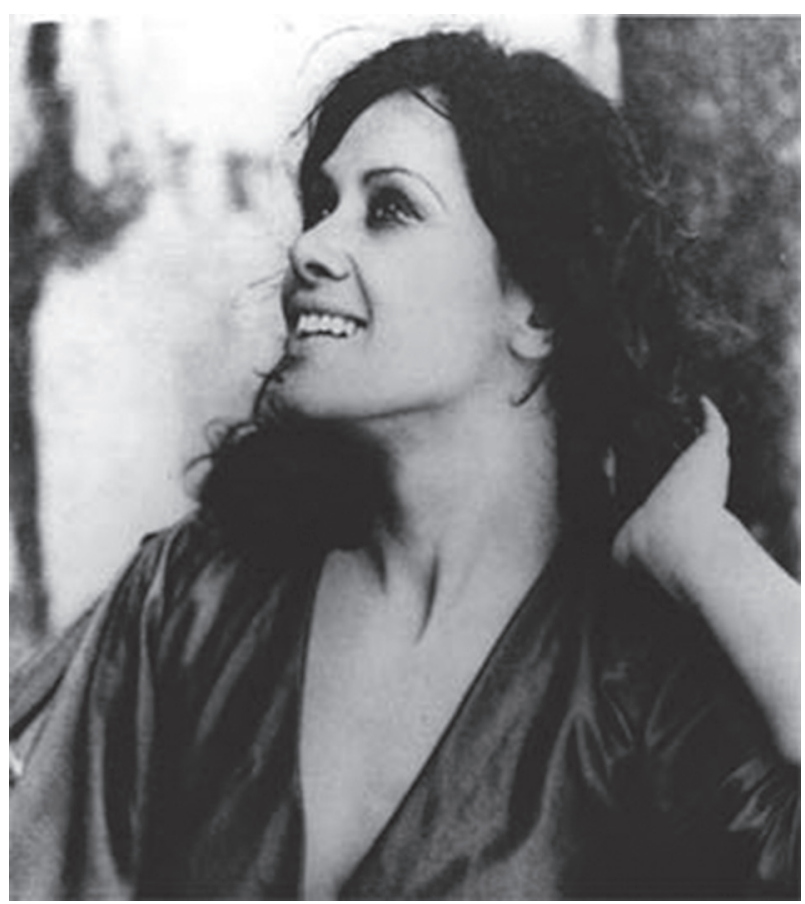

Dina Sfat

a sociedade mundial da primeira metade da década de 60, John Kenneth Galbraith afirmava: "O sistema industrial, nas suas mais profundas raízes, é dependente da televisão comercial e não poderia existir na sua forma atual sem ela” (GALBRAITH, 1972, p. 208).

No entanto, a televisão é apenas parte de um extenso processo de reprodução em massa de produtos culturais e entretenimento. A obra de arte, no capitalismo, entra na época da reprodutibilidade técnica, deixa de ser única e passa a ser reproduzida em massa. O cinema é particularmente significativo dessa nova fase: não há mais original strictu sensu, um filme é sempre visto de uma forma razoavelmente pradonizada - tratando-se, obviamente, de sua forma de exibição tradicional. Trata-se de uma mercadoria que se paga aos poucos: à medida que uma cópia é exibida e se cobra ingressos. Não há original, do ponto de vista comercial, quanto mais cópias, mais possibilidade de êxito.

O capitalismo cria um ramo da indústria, a chamada indústria cultural, que estabelece o princípio da mercadoria ao extremo. Os chamados bens culturais se estruturam a partir de elementos da personalidade, passando ser esta também produzida em escala industrial:

"Assim, por exemplo, o ar de obstinada reserva ou a postura elegante do individuo exibido numa cena determinada é algo que se produz em série exatamente como as fechaduras Yale, que só por fraçôes de milimetros se distinguem umas das outras. As particularidades do eu são mercadorias monopolizadas e socialmente condicionadas, que se fazem passam por algo de natural" (HORKEIMER e ADORNO, 1985, pp. 144-146).

Desaparece um tipo de transferência ${ }^{3}$ presente na cultura burguesa anterior à época da reprodutibilidade técnica. Que relação afetiva é possível entre espectador e bens

3Transferência, em psicanálise, é o processo pelo qual os desejos inconscientes se localizam em certos objetos, especialmente na relação analítica, assim o paciente estabelece uma relação afetiva especial com o médico. 
culturais no capitalismo atual, em particular, na televisão? $\mathrm{Na}$ seção seguinte, sobre televisão, ideologia e comportamento, apresentaremos algumas pistas.

$\mathrm{Na}$ indústria cultural também desaparece a distinção entre trabalho e diversão. A necessidade de reposição da força de trabalho se torna consumo, passando a ser também produzida (HORKEIMER e ADORNO, 1985, p. 128).

Os primeiros passos dessa transformação foram dados com a invenção da imprensa por Gutenberg em torno de 1450. Isso foi radicalmente acelerado com o advento do modo de produção capitalista que instalou a possibilidade de reproduzir em série a obra de arte. Teve importância notável a invenção da fotografia em 1822 e seus desdobramentos que inclui o surgimento do cinema em 1895. A reprodutibilidade técnica é o que assegura o aparecimento da arte como mercadoria, em outras palavras, a indústria cultural.

A indústria cultural tem sido vista a partir de dois enfoques de valores distintos: uma indústria que cumpre as funções do fascismo, promovendo a alienação do homem, por outro lado, é vista como instrumento de combate a essa mesma alienação.

A cultura como mercadoria se confunde tão cegamente com o uso que não se pode mais usá-la. A novela é uma repetição cada vez mais exaustiva de velhos plots e a canção popular apresenta formas melódicas degradadas para serem ouvidas no elevador ou no rádio que toca enquanto se prepara a mamadeira do bebê ou outra tarefa rotineira: "É por isso que ela se funde com a publicidade. Quanto mais destituída de sentido esta parece ser no regime do monopólio, mais todo-poderosa ela se torna" (HORKEIMER e ADORNO, 1985, p. 151).

A televisão no Brasil se consolidou no período da ditadura militar. No período anterior ao golpe de 1964, a Escola Superior de Guerra incluía a comunicação social como prioridade e que deveria "esclarecer a opinião pública sobre assuntos relacionados aos problemas nacionais bem com sobre as ações realizadas pelo governo para resolvê-los" (MATTOS, 2002, p. 30). O modelo de televisão implantado contará com sólido apoio do Estado na montagem da infraestrutura que permitirá a expansão privada da TV, em especial, da rede Globo:

"Durante os governos militares (1964-1985), o Estado exerceu papel decisivo no desenvolvimento e regulamentação dos meios de massa e em particular dos meios de transmissão, estabelecendo leis e agências reguladoras e adotando novas tecnologias no sistema nacional de telecomunicações. Foram instaladas as estações terrestres de satélites, ampliado o sistema telefônico e implantadas as linhas de micro-ondas, possibilitando ótima transmissão de TV em todo o território nacional" (MATTOS, 2002, p. 90).

A formação de uma rede nacional era um passo decisivo em direção à conquista do mercado publicitário. Nos primeiros anos, os patrocinadores determinavam os programas que deveriam ser produzidos e veiculados, além de contratarem diretamente os artistas e produtores. Assim, os programas eram identificados pelo nome do patrocinador: Repórter Esso, Gincana Kibon, Teatrinho Trol e outros.

À medida que a televisão se expande, sua participação no total das verbas publicitárias cresce até chegar aos $62 \%$ atuais (Exame.com.br). A abrangência da televisão é comprovada pelo dado que aponta sua presença em 84,3\% dos domicílios brasileiros, suplantando a presença de geladeiras (78,2\%) (MATTOS, 2002, p. 103). 
A escolha de um canal de televisão é feita pelo anunciante, determinada pelo índice de audiência aferido pelo instituto de pesquisa. No Brasil e nos demais países do Terceiro Mundo, a publicidade se concentra em comida, remédio e bens de consumo duráveis, assim se forma uma cadeia de relações industriais formada pela produção de bens gerais, a indústria publicitária e os meios de comunicação. Os chamados meios também são produtores de um tipo de indústria cultural e de indústria publicitária, esta última funcionando como o elo entre os demais setores.

\section{TV, comportamento e ideologia}

A televisão é o meio audiovisual que exerce mais influência no comportamento humano. A sua quase universalização e presença invasiva no ambiente doméstico oferece um tipo diferente de espetáculo - aquele que vem à casa do espectador. As pesquisas sobre televisão e comportamento têm levado em consideração os aspectos particulares de sua linguagem, especialmente, a montagem ou edição acelerada e o conteúdo da programação que transmitem.

Os estudos têm se concentrado nas repercussões do hábito de ver televisão entre as crianças, pois nesta fase se estruturaria o fundamental da personalidade.

A média mundial de permanência frente ao televisor é grande: situa-se entre $15 \mathrm{e}$ 30 horas semanais ou cerca de 4 horas por dia. Nos Estados Unidos, ver TV e Internet são atividades que rivalizam com o sono e do trabalho em quantidade de horas despendidas. A televisão fica ligada quase seis horas e meia por dia em cada família. É curioso notar que permanece cerca de $40 \%$ desse tempo sem que ninguém a assista (SARTORI, 1987, pp. 263-266).

Hoje o tempo em que se está conectado à Internet tende a ser cada vez maior: no Brasil, cerca de $85 \%$ dos jovens de 9 a 16 anos se conectam pelo menos uma vez por semana.

As pesquisas que procuram examinar a relação entre televisão e personalidade dão conta de uma influência televisiva importante na infância. Com base nos estudos psicológicos sobre identificação projetiva, projeção, introjeção e narcisismo ${ }^{4}$, e experiência clínica com crianças possuidoras de distúrbio de personalidade, Raquel Soifer fundamenta sua tese de que a assistência à televisão na infância hipertrofia o mecanismo de identificação projetiva, impedindo a utilização de outros mecanismos mentais como a introjeção, a sublimação e a reflexão, restringindo assim as possibilidades de crescimento intelectual (SOIFER, 1991, p. 24).

Que a imagem se vincula mais diretamente às emoções que a palavra é facilmente aceito, no entanto, há divergências quanto ao tipo de emoções desencadeadas. Para alguns, ver televisão ou qualquer espetáculo se assemelharia ao estado criado pelos sonhos. No entanto, esse estado não asseguraria a função do repouso, o que o privaria dos efeitos de proteção vital daqueles. É necessário dizer também que os sonhos formam-se a partir de situações reprimidas no inconsciente e que encontram expressão no estado de regressão criado (FREUD, 1978, pp. 213-218).

4A identificação projetiva é o que nos permite imaginar que entramos no outro e sentimos o mesmo que ele, nos levando a crer que somos esse outro. Os mecanismos de projeção organizam-se junto com a identificação projetiva e a introjeção, mediante a qual se incorporam as experiências vividas. A identificação projetiva permite o estabelecido do narcisismo, que se caracteriza pelo amor a nós mesmos, o egoísmo e a possessividade. Cf. LAPLANCHE e J.-B. PONTALIS, Vocabulaire de la psychanalyse. 
Herio Saboga e Virgínia Fontes sugerem que a linguagem da televisão não poderia ser análoga a dos sonhos, pois esta se articula como um compromisso entre $I d$ e Ego , não havendo na linguagem televisiva "contradição, negação ou impossíveis", ela se localizaria fora desse âmbito de compromisso:

"Linguagem dos sonhos ou do inconsciente, o fato é que as descrições das crianças diante de uma tela de televisão projetam uma imagem homogênea: postura relaxada, quase passiva, olhar morto, indiferença na absorção do conteúdo da tela, etc., numa espécie de demonstração prática da inutilidade de reação diante da realização imediata de um desejo. O discurso da televisão substitui a formulação de desejos pelas crianças, ofuxo ininterrupto de imagens propondo-se como resposta, por antecipação, a todos os desejos da criança" (SABOGA e FONTES, 1994, pp. 44).

A televisão introduziria dois agravantes ao processo: o acesso imediato tende a prolongar o número de horas destinadas ao acompanhamento de sua programação, e por outro lado, a televisão leva-nos sobremaneira à reclusão junto a ela, pois se encontra ao nosso alcance a qualquer momento (SOIFER, 1991, p. 15).

Acrescente-se a isso que a permanência prolongada das crianças frente ao aparelho de TV afasta-as de outras atividades que lhes ofereceriam maiores possibilidades de crescimento físico e mental. Sabemos a importância do brinquedo como estímulo à aprendizagem, à medida que funciona como um intermediário entre a fantasia e a realidade, permitindo desenvolver toda uma série de funções intelectuais, como concentração, memória, criação, recriação e raciocínio lógico.

Raquel Soifer aponta ainda o conteúdo da programação televisiva como fator que impede ultrapassar o pensamento mágico:

"O irracionalismo governa as ações; tudo é possivel e lícito: mortes, ressurreições, 'golpes', desabamentos, esmagamentos, explosóes e torturas, o que constitui uma clara expressão do pensamento mágico, em suas variações mais aberrantes e sinistras. $O$ sexo está sempre presente em manifestaçôes que chegam até a impudência e o descaramento" (SOIFER, 1991, p. 37).

A estruturação do pensamento lógico é um passo importante na formação da personalidade e da capacidade de elaboração, criando as condições para a argumentação válida, especialmente da inferência dedutiva e dos métodos de prova e demonstração.

Para Soifer, a televisão seria responsável por neurose caracterizada, entre outros aspectos, pela persistência da utilização maciça da identificação projetiva, indo muito além dos primeiros meses de vida, tendência à regressão até as fases iniciais do desenvolvimento mental e atenção dispersiva e dificuldade de concentração:

"É importante salientar que estes elementos psicopatológicos constituem por sua vez a estrutura sobre a qual se estabeleceu a dependência ao televisor, além de ser sua consequência. A fascinação que exercem as luzes, as imagens e os sons emitidos pelo televisor, origina-se no mecanismo de identificação projetiva maciça, em um processo semelhante ao que produzem os sonhos, os quais, definitivamente, formam-se para manter o sujeito adormecido".

5 Id é a parte mais antiga do aparelho psíquico, contendo tudo o que é herdado e se acha presente no nascimento, principalmente, os instintos, que aí encontram sua expressão psíquica. O Ego é o resultado do desenvolvimento de uma parte do $I d$, tem sob seu comando o movimento voluntário e sua principal tarefa é a autopreservação. Superego é resultado do longo período de influência dos pais e outros agentes externos e sua função principal é a limitação das satisfações. Cf. Sigmund FREUD, op. cit. pp. 199-201. 


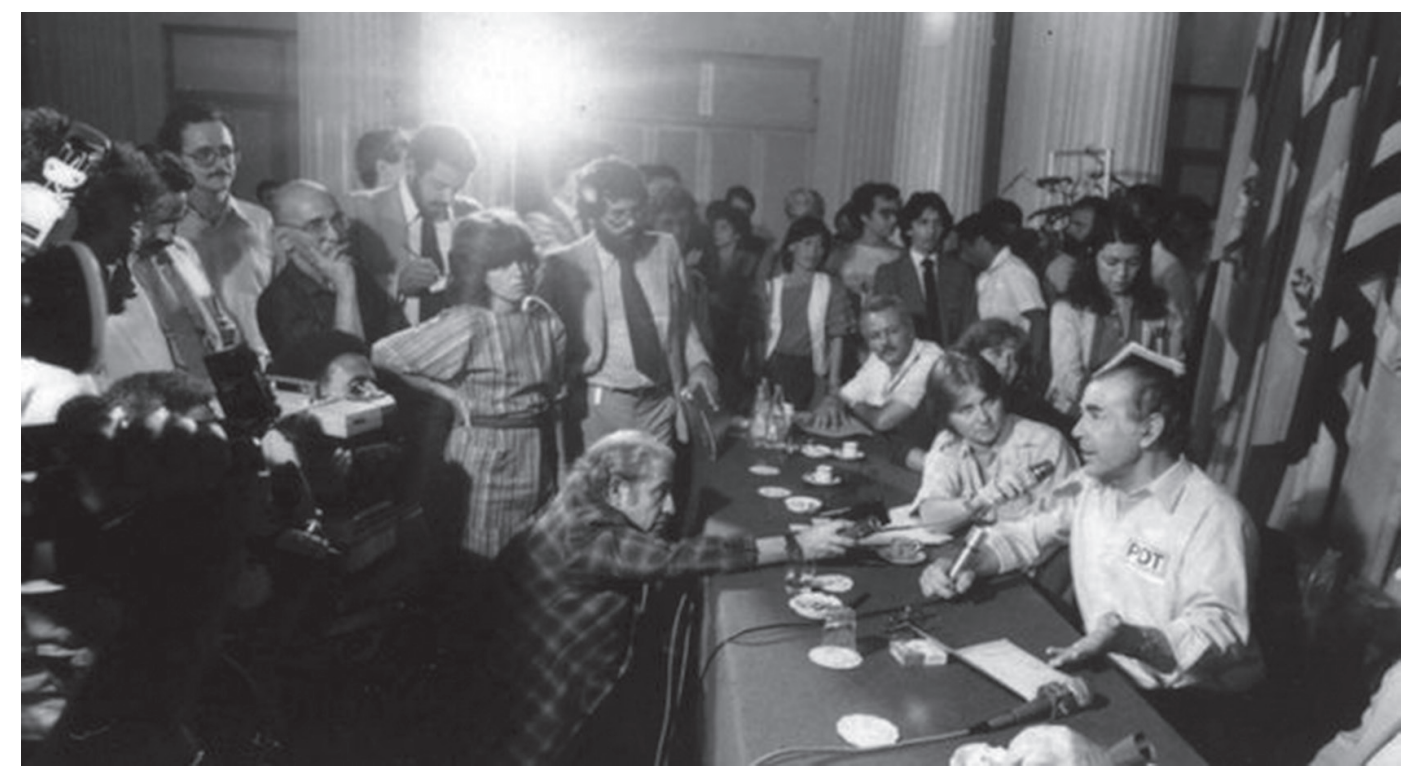

Brizola Fonte: http://jornalggn.com.br/

"Neste aspecto, a situação que se configura é semelhante à que estabelece o bebê com a chupeta: permite-lhe fantasiar que está se alimentando e chegar ao estado de alucinação. Em certa medida, também a contemplação prolongada de espetáculos televisivos leva a um estado parecido ao da alucinação" (SOIFER, 19991, p. 51).

A autora insiste que crianças até cinco anos não devem ver televisão, pois somente a partir dessa idade é possível diferenciar fantasia e realidade. Dos cinco anos em diante, deveriam vê-la de forma bastante restrita. ${ }^{6}$

Recentemente foi divulgada pesquisa da Universidade de Washington, Seattle, na qual se afirma que a rapidez da mudança de imagem na televisão é potencialmente danosa para o cérebro em formação das crianças. Elas experimentariam eventos de forma muito acelerada, contrastantes com a vida como ela se apresenta efetivamente.

\subsection{TV e telerrealidade}

Como meio técnico da realidade ou um tipo de espelho da realidade, a televisão inaugurou uma nova discussão sobre realidade e o que ela espelha - a chamada telerrealidade.

Sartori identifica duas formas essenciais de intervenção da televisão na criação da telerrealidade: os chamados media events (acontecimentos produzidos especialmente para a televisão), que passam a constituir o verdadeiro alimento da realidade e da história. $\mathrm{O}$ autor estabelece dois degraus da transformação da realidade em telerrealidade: o primeiro se dá quando a televisão se coloca a serviço da realidade, como no encontro de Sadat e Begin em Jerusalém, em 1978, combinado na televisão para acontecer em seguida, no segundo, a realidade se põe a serviço da televisão, como no

6Crianças entre 5 e 6 anos deveriam assistir meia hora por semana, crianças entre 7 e 8 anos duas vezes por semana, a partir dos 8 anos, três ou quatro vezes por semana, sem ultrapassar 1 hora, adolescentes não devem assistir mais de uma hora por dia, pp. 59-60. 
casamento do príncipe Charles da Inglaterra com a Lady Diana, em agosto de 1981 (SARTORI, 1987, pp. 271-273). ${ }^{7}$

Daniel Boorstin compreendera em 1961 a essência do fenômeno ao discorrer sobre os chamados "pseudo-acontecimentos": organização de um prêmio, celebração de um aniversário ou uma entrevista. Para o autor, os "pseudo-acontecimentos" tendem cada vez mais ocultar os eventos espontâneos, pois são mais "dramáticos", fáceis de difundir de maneira vívida e espetacular, custam dinheiro e tem a capacidade de gerar outros "pseudo-acontecimentos"(SARTORI, 1987, p. 274). Percy Tannenbaum ilustrou esta capacidade de "criação da realidade" com a frase: "Se uma árvore cai na TV, quer dizer que ela realmente caiu” (SARTORI, 1987, p. 270). (grifo do autor).

Podemos concluir que a televisão instaura dois problemas sérios: inibe a expressão do pensamento em razão do ritmo veloz que adota, obrigando tanto aqueles que emitem mensagens a pensarem "mais rápido que sua sombra", na expressão de Pierre Bourdieu (pp. 38-41), e dificulta a reflexão por parte dos receptores à medida que os absorvem como participantes do espetáculo. Como refletir se faço parte do show?

A televisão como aparelho ideológico de Estado incorpora elementos próprios de sua linguagem na estruturação da ideologia dominante, especialmente na eliminação do sentido crítico da história, estabelecida por essa impossibilidade de reflexão com a instauração do primado do "aqui e agora".

\section{Telejornalismo}

O telejornalismo é a mais importante fonte de informação para a maioria da população brasileira, sendo o tipo de programação preferida de $87,4 \%$ dos homens e 71,3\% das mulheres. Para dimensionar a importância desse dado, lembremos que o hábito da leitura de jornais atinge apenas $5 \%$ da população.

A prática da justaposição de informação é uma regra geral nos telejornais. Vejamos um exemplo de cobertura telejornalística: o presidente do Congresso solicitou licença de seu cargo; a seguir, ficamos sabendo que os presumidos atos de corrupção daquele parlamentar continuam a ser investigados; mais adiante, informa-se que o presidente da República está acompanhando o caso, mas não irá se manifestar por enquanto. Verificamos a ausência de quaisquer relações mais substantivas ou complexas entre os fatos (FISHER, 2003, p. 104).

Outro aspecto significativo é o registro dos índices de pouca atenção dos telespectadores que algumas pesquisas apontam - apenas 18\% acompanham atentamente os programas jornalísticos. Pesquisa feita com pessoas de baixa renda e estudantes mostrou que aproximadamente $70 \%$ das informações do Jornal Nacional (JN) não são absorvidas, em virtude do ritmo acelerado da edição (TILBURG, 1990, pp. 88-91).

O $J N$ foi ao ar pela primeira vez em setembro de 1969 e sua equipe inicial vinha da imprensa escrita, ao contrário de outras experiências de telejornalismo que eram oriundas do rádio. É o segundo programa em audiência da emissora e sua importância na formação da opinião é grande em razão do percentual pequeno de leitores de jornal, como já vimos.

No período da ditadura de 1964, a censura e a autocensura eram recorrentes: não se deveria mencionar que ex-presidente Juscelino Kubitschek tivera os direitos

7 Anuar Sadat, presidente do Egito de 1970 a 1981, e Menachen Begin, primeiro-ministro de Israel eleito em 1977, assinaram os acordos de paz de Camp David em 1978/1979. 
políticos cassados; nos funerais de Mao Tse-tung não se deveria mencionar a palavra "líder". Nas palavras do ditador Emílio Médici (1969-1974), o Jornal Nacional era um tranquilizante após um dia de trabalho" (MATTOS, 2002, p. 104).

Em 1984, o $J N$ boicotou o início da campanha das diretas, que visava pôr fim a ditadura. Outra ostensiva tomada de posição ocorreu na célebre edição do debate presidencial de 1989, quando houve um tratamento claramente favorável ao candidato Fernando Collor de Melo.

\section{Teledramaturgia}

No Brasil, a teledramaturgia inclui telenovelas, minisséries e telepeças. Essa última modalidade é hoje bastante rara e o que se faz ainda com alguma frequência são dramatizações de casos policiais célebres. Em razão de sua importância merece especial atenção a telenovela.

O termo telenovela permite alguma confusão. Ao contrário do conceito novela no plano literário não se trata de narrativa curta. O equívoco vem da palavra novela que em espanhol é sinônimo de romance e sabe-se que os primeiros espetáculos, ainda no rádio, eram adaptações de roteiros oriundos de países de língua espanhola. A narrativa longa aproxima a telenovela do romance, mais exatamente do romance-folhetim e do melodrama. Do folhetim ela adota a narrativa em capítulos e o hibridismo, com a presença das diferentes classes sociais e mudanças sociais impressionantes. A ênfase na divisão absoluta entre o Bem e o Mal é oriunda do melodrama ${ }^{8}$, onde as relações humanas são simplificadas ao extremo.

A telenovela é narrativa parcelada com universo pluriforme, onde se desenvolvem simultaneamente vários plots ou tramas, formando o multiplot. O plot principal será aquele que, num dado momento, se mostrar o favorito do público. Os plots mais usuais são os do amor, do sucesso, da cinderela, do triângulo amoroso, da volta, da vingança, da conversão; do sacrifício e da família.

A narrativa na telenovela tem duas características básicas: o culto à peripécia, onde os fatos não ocorrem, acontecem, isto é, estão prenhes de consequências, e a sucessividade, que implica na manipulação do suspense, necessário para a duração da série, para tal é necessário destacar o campo da emoção, afastando-se de âncoras como o tempo histórico no qual a narração se dá e onde vive o telespectador" (CAMPDELLI, 1985, pp. 20-23).

Os plots também podem ser vistos como mitos, como indica claramente o plot Cinderela; o plot sacrifício está diretamente associado aos mitos dos suplícios (Prometeu, Tântalo e Sísifo). Para Artur da Távola, as limitações do incurso ideológico abrem possibilidades para a emergência do conflito mitológico (TÁVOLA, 1996, pp. 28-29), que pode ser livremente abordado.

A telenovela surge no ano seguinte ao da televisão no Brasil e recebe grande estímulo com o uso do videoteipe, no início da década de 60. As primeiras telenovelas eram apresentadas ao vivo, em dois capítulos semanais. Sua vida me pertence inaugurou o ciclo em 1951. Em 1963, a apresentação em capítulos diários tem início

$8 \quad$ Folhetim é narrativa longa parcelada, desenvolvida segundo trançamentos dramáticos, apresentados gradualmente. Originalmente os folhetins eram publicados nos rodapés dos jornais. O melodrama é originário do teatro e o nome deve-se ao fato dos atores representarem cantando. Surgiu no século XVI em Florença e evoluiu até chegar ao cinema, ao radioteatro e às telenovelas. 
com o drama 2.5499 Ocupado. No entanto, o gênero só se consolida em 1965, com o sucesso de $O$ direito de nascer, na sua primeira versão com Amilton Fernandes, Guy Loup e Nathalia Timberg.

A fase de amadurecimento do gênero pode ser caracterizada com o lançamento de Beto Rockfeller, de Bráulio Pedroso em 1968 e Roque Santeiro, de Dias Gomes e Aguinaldo Silva, em 1985. Bons atores, autores teatrais qualificados e diretores formados pela própria televisão asseguraram um padrão artístico que se conjugou com os padrões mercadológico e produtivo.

A teledramaturgia televisiva no Brasil é quase exclusivamente a telenovela. $\mathrm{O}$ gênero tem importância fundamental, tanto no envolvimento do público como na sustentação do negócio televisivo, sendo às vezes responsável por lucros 25 vezes o valor do investimento.

A telenovela se insere na larga tradição do melodrama tão enraizada no modo de ser dos povos da América Latina e alcança no seu período áureo um grau de criatividade e padrão de produção bastante elevados. A exportação do produto para diversos países confirma esse amadurecimento. Desde algum tempo, o modelo tem dado sinais de crise, mas o que temos pela frente é um quadro bastante incerto - e a sua solução certamente está ligada a possibilidade de camadas amplas da população se manifestarem de forma ativa sobre os rumos da produção da arte e da cultura.

\section{Considerações finais}

No caso da telenovela a estética da superficialidade não impede que desenvolva importante função de mobilização emocional: as cargas emocionais impedidas de ter seu curso no dia-a-dia de um trabalho cada vez mais desumanizado são exercitadas ainda que de modo indireto e projetivo (TÁVOLA, 1996, p. 114).

Como principal produto televisivo, a telenovela tem com a publicidade compromissos muito estreitos, no entanto, ao trabalhar com tramas e mitos, que lhe oferecem maior liberdade que o tratamento da notícia permite, especialmente no período de 1970 a meados da década de 1980, tem sido um produto de grande influência na programação social dos comportamentos naquilo que é lhe é específico: a mobilização emocional.

Quanto ao telejornalismo, se no tratamento das notícias a ideologia estaria desacompanhada do mito e da trama, o que faz sua mensagem parecer neutra? Ou essa busca por neutralidade encontra cada vez mais obstáculos na medida em que se intensifica a crise de transição do capitalismo?

No telejornalismo, como vimos a criação de uma telerrealidade cria tensões que a tentativa de não incorporar o início da campanha das diretas ao noticiário da maior rede de televisão é um exemplo, permitindo afirmar que ali o confronto entre realidade e telerrealidade se tornou visível.

Tais observações preliminares indicariam que a telenovela estaria cumprindo uma função integradora e o telejornalismo fonte de mal-estar? Estaria deixando de ser a "ilha de tranquilidade" e revelando posições de classe mais explícitas, como tem sido notado na cobertura das eleições presidenciais e outros fatos políticos recentes?

Observa-se com facilidade mudanças de hábito dos telespectadores frente à mídia televisiva e dos produtos-programas veiculados, mas não sabemos a direção destas tendências, historicamente não foram no sentido de afirmar ações e princípios que possam assegurar o controle democrático sobre tais produções, o que faz com que 
pesquisas procurem identificar as contradições capazes de compreender os novos rumos da produção de telejornais e telenovelas.

\section{Referências bibliográficas}

ADORNO, T. W. e HORKHEIMER, M. Dialética do esclarecimento. Trad. Guido A. de Almeida. Rio de Janeiro: Jorge Zahar, 1985.

BEVILAQUA, Aluisio. A Crise do Capital em Marx e suas Implicações nos Paradigmas da Educação. Rio de Janeiro: Editora Inverta/Edições UFC, 2011.

BOURDIEU, Pierre. Sobre a televisão. Trad. Maria Lúcia Machado. Rio de Janeiro: Jorge Zahar Ed., 1997.

CARDOSO, Ciro Flamarion. Ensaios racionalistas. Rio de Janeiro: Campus, 1988.

CAMPDELLI, Samira Youssef. A telenovela. São Paulo, Ática, 1985 (Coleção Princípios).

COELHO NETTO, José Teixeira Coelho. O que é indústria cultural. 6a ed. São Paulo: Brasiliense, 1983 (Coleção Primeiros Passos).

COMPARATO, Doc. Roteiro. Arte e técnica de escrever para cinema e televisão. Rio de Janeiro, Nórdica, 1983.

ECO, Umberto. Apocalipticos e integrados. $5^{\mathrm{a}}$ ed. Trad. Pérola de Carvalho. São Paulo, Perspectiva, 1998.

FERNANDES, Ismael. Memória da telenovela brasileira. São Paulo: Proposta Editorial, 1982.

FISHER, Rosa Maria B. Televisão e educação: fruir e pensar a TV. Belo Horizonte: Autêntica Editora, 2003.

GIACOMANTONIO, Marcello. O ensino através dos audiovisuais. Trad. Danilo Morales e Riccarda Ungar. São Paulo, Summus: Editora da Universidade de São Paulo, 1981.

GIANNOTTI, Vito. Comunicação dos trabalhadores e hegemonia. São Paulo: Editora Perseu Abramo, 2014.

HOINEFF, Nelson. A nova televisão; desmassificação e o impasse das grandes redes. Rio de Janeiro: Relume Dumará, 1996.

HORKHEIMER, Max e ADORNO, Theodor W. Dialética do esclarecimento: fragmentos filosóficos. Trad. Guido A. de Almeida. Rio de Janeiro: Jorge Zahar, 1985.

KEHL, Maria Rita. Imaginar e pensar. In NOVAES, Adauto (org.). Rede imaginária: televisão e democracia. 2a ed. São Paulo: Companhia das Letras/Secretaria Municipal de Cultura, 2001, pp.60-72.

LEAL FILHO, Laurindo. Atrás das câmeras; relações entre cultura, Estado e televisão. São Paulo, Summus Editorial, 1988.

MATTOS, Sérgio. História da televisão brasileira: uma visão econômica, social e politica. 2a ed. Petrópolis: Vozes, 2002.

REY, Marcos. O roteirista profissional: televisão e cinema. 3a ed. São Paulo: Ática, 1997. TÁVOLA, Artur. A telenovela brasileira. História, análise e conteúdo. São Paulo: Globo, 1996.

TILBURG, João Luís van. A televisão e o mundo do trabalho. São Paulo: Edições Paulinas, 1990.

SABOGA, Herio e FONTES, Virgínia. Escola, televisão e cidadania. À margem, Rio de Janeiro, (4): 40-50, 1994. 
SARTORI, Carlo. O olho universal. In GIOVANINI, Giovani (org.). Evolução na comunicaşão; do sílex ao silício. Trad. Wilma Freitas e Ronald de Carvalho. Rio de Janeiro: Nova Fronteira, 1987, pp. 249-280.

SOIFER, Raquel. A criança e a TV: uma visão psicanalitica. Trad. Iara Rodrigues. Porto Alegre: Artes Médicas, 1991. 